\title{
Epidemiology of Community Origin Escherichia coli and Klebsiella pneumoniae Uropathogenic Strains Resistant to Antibiotics in Franceville, Gabon
}

Yann Mouanga Ndzime ${ }^{1,2}$

Richard Onanga (iD)'

Roland Fabrice Kassa Kassa'

Michelle Bignoumba (D) '

Pierre Philippe Mbehang Nguema (ID)

Amahani Gafou'

Roméo Wenceslas Lendamba'

Kelly Mbombe Moghoa'

Cyrille Bisseye (iD ${ }^{2}$

'Unité de Recherche et d'Analyses Médicales, Laboratoire de Bactériologie, Centre Interdisciplinaire de Recherches Médicales de Franceville, Franceville, BP 769, Gabon; ${ }^{2}$ Laboratoire de Biologie Moléculaire et Cellulaire (LABMC), Université des Sciences et Techniques de Masuku, Franceville, BP 943, Gabon; ${ }^{3}$ Institut de Recherche en Ecologie Tropicale, Centre National de la Recherche Scientifique et Technologique (CENAREST), Libreville, BP I3354, Gabon
This article was published in the following Dove Press journal: Infection and Drug Resistance

Introduction: Urinary tract infection is one of the major causes of consultation, microbiologic exploration, intensive use of antibiotics worldwide, and the second leading cause of clinical consultation in community practice. Many bacteria play a role in the urinary tract infections etiology, including Enterobacteriaceae such as Escherichia coli (E. coli) and Klebsiella spp.

Objective: The study's main objective was to examine the epidemiology of E. coli and Klebsiella pneumoniae (K. pneumoniae) uropathogenic strains resistant to antibiotics in Franceville.

Methodology: The study was carried out between January 2018 and June 2019 in Franceville South-East Gabon. We examined a total of 1086 cytobacteriological urine samples. The identification of E. coli and K. pneumoniae strains was carried out using the Vitek-2 compact automated system and the antibiogram with the disk diffusion method according to the European Committee on Antimicrobial Susceptibility Testing recommendations.

Results: The prevalence of urinary tract infections was $29.2 \%$ (317/1086), of which $25.1 \%$ and $4.1 \%$ were mono-infections and co-infections, respectively. The prevalence of UTIs with E. coli was $28.7 \%(91 / 317)$ with a predominance of isolation in women. K. pneumoniae was responsible for $16.2 \%(61 / 317)$ of UTIs. E. coli and $K$. pneumoniae Uropathogenic strains showed resistance to beta-lactams, quinolones and cotrimoxazole, whereas Nitrofurantoin, Amikacin, Imipenem and Ertapenem were the most active antibiotics against E. coli and K. pneumoniae uropathogenic strains.

Conclusion: This study showed a high prevalence of urinary tract infections with a major implication of E.coli and K. pneumoniae strains. E. coli and K. pneumoniae presented high frequency of resistance to antibiotics, highlighting the need to adapt their use accordingly at the local level.

Keywords: urinary tract infection, antibiotic resistance, E. coli, K. pneumoniae

\section{Introduction}

Urinary tract infections (UTIs) are the second most common ailment in community medical practice. Each year, around 150 million people are diagnosed worldwide with urinary tract infections costing more than 6 billion US dollars to the global economy. ${ }^{1}$ UTIs are a major global public health problem, because of the health costs they cause and the selection of multidrug-resistant strains both in hospitals and in community settings. ${ }^{2}$ These are common infections with an alarming
Correspondence: Yann Mouanga Ndzime Tel +24177206217

Email yann_mouangandzime@yahoo.fr 
increase in resistance to last-resort antibiotics. ${ }^{3}$ Many bacteria are involved in the etiology of urinary tract infections, including enterobacteria such as $E$. coli and Klebsiella spp. ${ }^{4}$ These bacteria are the most common pathogens in UTIs. However, less common agents may also cause UTIs, such as non-fermenters and fungi. ${ }^{5,6}$

Several studies conducted in Europe and the United States of America have shown a constant increase in the rate of resistance of uropathogenic bacteria to commonly prescribed antibiotics leading to reduced therapeutic efficacy. $^{7}$

The main risk factor for resistance to an antibiotic is repeated previous exposure to the same antibiotic. Indeed, the misuse of an antibiotic or a class of antibiotics is the cause of development of bacterial resistance, possibly extending to other families of antibiotics because of the cross-transmission of mobile genetic elements carrying antibiotic resistance genes. ${ }^{8,9}$ These bacterial resistances develop more easily in the digestive microbiota due to a large number of bacteria (greater than $10^{9}$ bacteria per gram of stool), promoting contact as well as the emergence of resistant mutants. UTIs are most often of ascending origin by contamination from the perineal flora, reflecting the digestive flora. Therefore this selection pressure has a definite clinical impact. ${ }^{8}$

Early treatment of UTIs decreases their severity rate, which, in most cases, involves antibiotic treatment prescribed empirically. ${ }^{10}$ In order to administer appropriate therapy, it is essential to identify the main bacteria commonly involved in urinary tract infection and their antibiotic resistance profile. ${ }^{11}$ In Gabon, the lack of treatment regimen standardization and clinical bacteriology laboratories make essential studies on uropathogenic germs and their susceptibility and/or resistance to antibiotics providing a local profile of bacterial resistance.

This study aimed to determine the epidemiology of Escherichia coli and Klebsiella pneumoniae uropathogenic strains isolated from patients in consultation at the Interdisciplinary Center for Medical Research of Franceville in South-East Gabon and to determine their resistance profile to common antibiotics.

\section{Materials and Methods}

\section{Patients}

The study was carried out between January 2018 and June 2019. It involved all patients from the community requesting a cyto-bacteriological examination of urine
(CBEU) by the laboratory of medical analyzes, which is the only bacteriology laboratory in the city of Franceville, capital of the Haut-Ogooué province, the second-most populous province of Gabon bordering the Republic of Congo.

Patients of all ages and both sexes who presented for a CBEU were considered eligible for the study.

\section{Sample Collection}

Urine samples were preferably collected in the morning or after an absence of urination for about 4 hours, either in the laboratory or at home, under strict aseptic conditions. Urine was collected in a sterile, single-use urine container.

For children who could use the toilet on their own, urine samples were collected using a sterile adhesive collection bag under the supervision of a guardian. The urine vial was then sealed, identified, indicating the time of collection and then transported by the patient at room temperature to the laboratory. The socio-demographic and clinical data for each patient were collected through a structured questionnaire.

\section{Culture and Identification of Bacterial Isolates}

It consisted of inoculating ten (10) $\mu \mathrm{L}$ of total urine aseptically using a sterile single-use loop in the level 2 microbiological safety station. The inoculation was carried out systematically on agar media, CLED (Cystine-Lactose -Electrolytes-Deficient; Biomérieux, France), Mac Conkey (McC, Biomérieux, France), Eosin Methylene Blue (EMB, Biomérieux, France) after briefly homogenizing the urine. Urine samples were inoculated within two (2) hours of collection to avoid false positives. The inoculated media were systematically incubated aerobically in a bacteriological oven at $35^{\circ} \mathrm{C}$ for 18 to 24 hours. According to Kass criteria a number $\geq 10^{5}$ colony forming units $(\mathrm{CFU}) / \mathrm{mL}$ of urine was considered positive; a colony number $<10^{5} \mathrm{CFU} / \mathrm{mL}$ or with more than two (2) types of bacterial colonies were considered contaminated. ${ }^{12}$

The identification of $E$. coli and $K$. pneumoniae strains was done after Gram stain, oxidase test and conventional biochemical tests (VITEK-2 automated system, Biomérieux, France). Only E. coli and $K$. pneumoniae strains isolated in monoinfected culture were retained in the study.

\section{Antibiotic Sensitivity Test}

All $E$. coli and $K$. pneumoniae isolates were tested for sensitivity to the following antibiotics: ampicillin, 
ticarcillin, amoxicillin-clavulanic acid, cefalotin, cefoxitin, cefotaxime, ceftazidime, cefepime, imipenem, ertapenem, gentamicin, tobramycin, amikacin, ofloxacin, ciprofloxacin, nalidixic acid, trimethoprimsulfamethoxazole, nitrofurantoin according to the diffusion disc method (Kirby-Bauer) on Mueller-Hinton (MH) agar according to the recommendations of the European Committee on Antimicrobial Susceptibility Testing (EUCAST, V. 2.0 2018). ${ }^{13}$ Briefly, MH agars were seeded with a standardized suspension (0.5 McFarland) of each E. coli and K. pneumoniae isolate for a 24 hour $\mathrm{MH}$ agar culture. The antibiotic discs were firmly placed on the surface of the seed plates. The culture media were then incubated for 24 hours at $35^{\circ} \mathrm{C}$. The diameters of antibiotics inhibition zones were interpreted according to the recommendations of the EUCAST. ${ }^{13}$ Multi-drug resistance (MDR) was defined as non-susceptibility to at least one agent in three or more antimicrobial categories. ${ }^{14}$

\section{Statistical Analysis}

All the data collected was entered in a Microsoft Excel 2013 file and then analyzed by the $\mathrm{R}$ software (version $\mathrm{R} \times$ 64.3.4.3). The differences were considered significant for $\mathrm{p}<0.05$.

\section{Ethical Considerations}

Informed and written consent was obtained from each adult patient prior to inclusion in the study. With regard to minors, consent has been obtained from their parents or legal guardians.

The research licence for this study was obtained from the Scientific Commission on Research Authorisations of the National Centre of Scientific and Technological Research (CENAREST) (permit 7 no. AR0033/17/ MESRSFC/CENAREST/CG/CST/CSAR, dated 4 July 2017). This study was conducted in accordance with the Declaration of Helsinki.

\section{Results}

\section{Characteristics of Patients}

Of 1086 CBEUs performed, 61.7\% (670/1086) were from female patients. The mean age of patients was $24.7 \pm 18.9$ years. More than half of these were aged 18 to $49(53.7 \%)$. The vast majority of patients came from the city of Franceville $(72.2 \%)$ and did not present any particular morbid ground
(94.3\%). Among these patients, $58.8 \%$ had urinary signs, and $86.8 \%$ of samples were collected mid-stream (Table 1).

\section{Prevalence of Urinary Tract Infections Due to $E$. coli and $K$. pneumoniae}

The overall prevalence of UTIs was $29.2 \%$ (317/1086), of which $25.1 \%$ (273/1086) were mono-infections while $4.1 \%$ (44/1086) were co-infections. Contaminations represented $23.2 \%(252 / 1086)$ of cultures, whereas $0.3 \%(3 / 1086)$ of CBEUs showed significant bacteriuria without leukocyturia.

The prevalence of UTIs due to E. coli was $28.7 \%(91 /$ 317 ) with $24.6 \%$ (78/317) of mono-infections and $4.1 \%$ (13/317) of co-infections. Regarding co-infections, E. coli was associated with $K$. pneumoniae $(0.3 \%), K$. oxytoca (0.3\%), E. faecalis (0.9\%), Staphylococcus spp. (1.3\%), $S$. agalactiae $(0.3 \%)$, E. aerogenes $(0.3 \%)$, E. cloacae complex $(0.63 \%)$ (Table 2$)$.

K. pneumoniae was found in $18.9 \%(60 / 317)$ of urinary tract infections with $14.2 \%(45 / 317)$ of the strains isolated in monoculture while $4.7 \%(15 / 317)$ were identified in association with $K$. oxytoca (0.3\%), Enterococcus spp.

Table I Socioclinical Characteristics of the Study Patients

\begin{tabular}{|l|l|l|}
\hline Characteristics & Number & Percentage \\
\hline Sex & & \\
Male & 416 & 38.3 \\
Female & 670 & 61.7 \\
\hline Age groups & & \\
$\leq 5$ years & 284 & 26.2 \\
$6-17$ years & 110 & 10.1 \\
I8-49 years & 583 & 53.7 \\
$\geq 50$ years & 109 & 10.0 \\
\hline Locality & & \\
Franceville & 784 & 72.2 \\
Outside Franceville & 302 & 27.8 \\
\hline Underlying terrain & & \\
None & 1024 & 94.3 \\
Comorbidity & 62 & 5.7 \\
Symptoms & & \\
Urinary signs & 638 & 58.7 \\
Non-urinary signs & 344 & 31.7 \\
None & 104 & 9.6 \\
\hline Sampling methods & & 13.1 \\
Collector pocket & 142 & 0.1 \\
Mid-jet & 943 & \\
Urinary catheters & 1 & \\
\hline
\end{tabular}


Table 2 Isolation of Uropathogenic Bacteria

\begin{tabular}{|c|c|c|}
\hline Urinary Infections & $\begin{array}{c}\text { Number } \\
(n=3 \mid 7)\end{array}$ & $\begin{array}{c}\text { Percentage } \\
\text { (\%) }\end{array}$ \\
\hline \multicolumn{3}{|l|}{ Mono-infection } \\
\hline E. coli & 78 & 24.6 \\
\hline K. pneumoniae & 45 & 14.2 \\
\hline Other Enterobacteriaceae & 20 & 6.3 \\
\hline Non-fermenting GNB & 11 & 3.5 \\
\hline S. saprophyticus & 19 & 6.0 \\
\hline S. aureus & 14 & 4.4 \\
\hline Coagulase negative Staphylococcus & 45 & 14.2 \\
\hline E. faecalis & 21 & 6.6 \\
\hline E. faecium & 4 & 1.3 \\
\hline Streptococcus spp. & 6 & 1.9 \\
\hline Other Gram positive cocci & 5 & 1.6 \\
\hline C. albicans & 5 & 1.6 \\
\hline \multicolumn{3}{|l|}{ Co-infections } \\
\hline E. coli/K. pneumoniae & I & 0.3 \\
\hline E. coli/K. oxytoca & 1 & 0.3 \\
\hline E. coli/E. faecalis & 3 & 0.9 \\
\hline E. coli/Staphylococcus spp. & 4 & 1.3 \\
\hline E. coli/S. agalactiae & I & 0.3 \\
\hline E. coli/E. aerogenes & I & 0.3 \\
\hline E. coli/E. cloacae complex & 2 & 0.63 \\
\hline K. pneumoniae/K. oxytoca & 1 & 0.3 \\
\hline K. pneumoniae/Enterococcus spp. & 7 & 2.2 \\
\hline K. pneumoniae/Staphylococcus spp. & 6 & 1.9 \\
\hline K. pneumoniae/P. acidilactici & 1 & 0.3 \\
\hline C. freundii/E. faecalis & $\mathrm{I}$ & 0.3 \\
\hline E. cloacae/E. faecalis & I & 0.3 \\
\hline E. cloacae/A. denitrificans & 1 & 0.3 \\
\hline P. mirabilis/S. marcescens & I & 0.3 \\
\hline P. mirabilis/C. freundii & I & 0.3 \\
\hline S. fonticola/S. haemolyticus & 1 & 0.3 \\
\hline R. ornithinolytica/Enterococcus spp. & 1 & 0.3 \\
\hline E. faecalis/E. faecium & I & 0.3 \\
\hline E. faecalis/S. saprophyticus & I & 0.3 \\
\hline E. faecalis/A. salmonicida & I & 0.3 \\
\hline S. epidermidis/C. albicans & 1 & 0.3 \\
\hline S. epidermidis/S. haemolyticus & 1 & 0.3 \\
\hline S. saprophyticus/A. baumanii & 1 & 0.3 \\
\hline S. saprophyticus/Streptococcus spp. & 1 & 0.3 \\
\hline S. haemolyticus/S. porcinus & I & 0.3 \\
\hline S. haemolyticus/S. capitis & I & 0.3 \\
\hline
\end{tabular}

(2.2\%), Staphylococcus spp. (1.9\%), or P. acidilactici $(0.3 \%)$ (Table 2).

\section{Distribution of Urinary Mono-Infections Due to $E$. coli and $K$. pneumoniae}

A total of $78 \mathrm{E}$. coli urinary mono-infections were identified in the CBEUs of patients. These E.coli mono- infections were significantly more frequent in women compared to men $(82 \%$ vs $18 \%$; p <0.001) (Figure 1). The frequency of $E$. coli UTIs was significantly lower in patients aged 6-17 years compared to those aged $\leq 5$ years $(7.7 \%$ vs $25.6 \% ; \mathrm{p}=0.03)$ and $18-49$ years $(7.7 \%$ vs $52.6 \% ; \mathrm{p}<0.001)$. In addition, E. coli was found predominantly in patients with urinary signs compared to those without urinary signs (68\% vs $32 \%$; $<<0.001)$ (Figure 1$)$.

Regarding the seasons, E. coli UTIs were significantly more frequent in the short rainy season compared to the short dry season $(35.9 \%$ vs $17.95 \% ; \mathrm{p}=0.012)$ or the long rainy season $(35.9 \%$ vs $19.23 \% ; \mathrm{p}=0.02)$ (Figure 1 ).

A total of $45 \mathrm{~K}$. pneumoniae UTIs were identified in patients' CBEUs. K. pneumoniae was found significantly more often in women than in men $(66.7 \%$ vs $33.3 \%$; $\mathrm{p}=$ 0.002 ). It was associated with patient age being significantly lower in the 6-17 years age group compared to the $\leq 5$ years $(4.4 \%$ vs $55.6 \% ; \mathrm{p}<0.001)$ and $18-49$ years age groups (4.4\% vs $28.9 \%$; $\mathrm{p}=0.002)$ (Figure 1$)$. In addition, the distribution of UTIs due to K. pneumoniae was associated with seasonality and was more frequent during the short rainy season compared to the long dry season $(37.8 \%$ vs $13.3 \% ; \mathrm{p}=0.008$ ) (Figure 1 ).

\section{Antibiotic Resistance Assessment of $E$. coli and $K$. pneumoniae Isolates}

Of the 123 strains of E. coli and K. pneumoniae isolated, the highest rates of antibiotic resistance were observed with Ampicillin (78\%), Ticarcillin (75\%), TrimethoprimSulfamethoxazole (63\%), Cefalotin (47\%), Amoxicillinclavulanic acid (44\%), Cefotaxime (41\%), and Nalidixic acid $(40 \%)$. The majority of bacterial strains isolated (56\%) were multidrug resistant (MDR) (Table 3).

Overall, beta-lactam resistance was significantly more frequent in MDR strains compared to non-MDR strains for Ampicillin ( $\mathrm{p}<0.001)$, Ticarcillin $(\mathrm{p}<0.001)$, Amoxicillinclavulanic acid ( $\mathrm{p}<0.001)$, Cefalotin $(\mathrm{p}<0.001)$, Cefoxitin ( $\mathrm{p}<0.001)$, Cefotaxime ( $\mathrm{p}<0.001)$, Ceftazidime ( $\mathrm{p}$ $<0.001)$ and Cefepime $(\mathrm{p}=0.026)$ (Table 3$)$. This was also observed with quinolones including Nalidixic Acid ( $p$ $<0.001$ ), Ciprofloxacin ( $<<0.001$ ) and Ofloxacin ( $p$ $<0.001)$; and with aminoglycosides such as Gentamicin $(\mathrm{p}<0.001)$, Tobramycin $(\mathrm{p}<0.001)$ and Amikacin $(\mathrm{p}=$ 0.026) (Table 3). Furthermore, resistance to TrimethoprimSulfamethoxazole was more prevalent in MDR strains compared to non-MDR strains $(\mathrm{p}<0.001)$ (Table 3 ). 


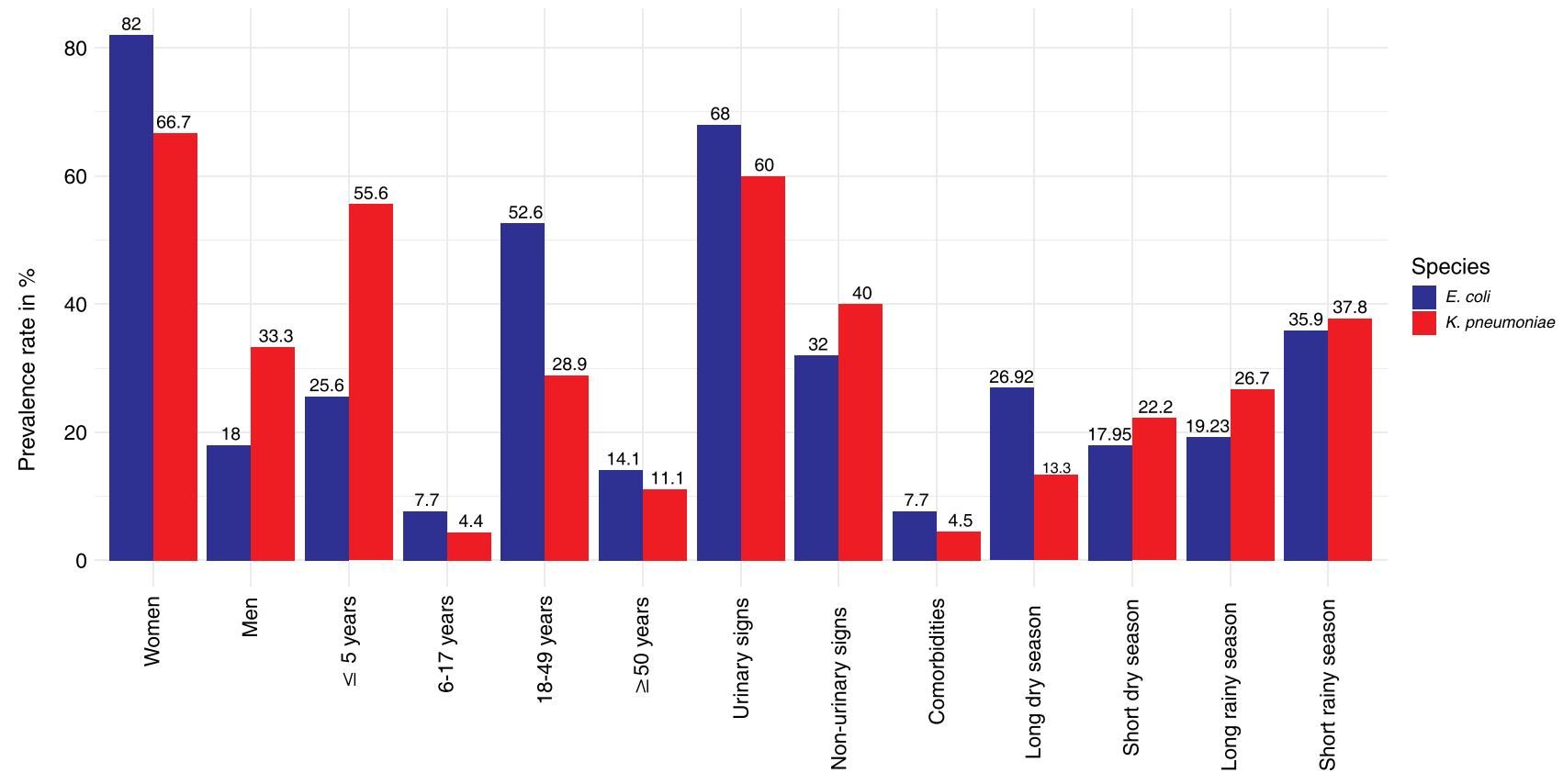

Socioclinical parameters

Figure I Distribution of $E$. coli and K. pneumoniae urinary mono-infections according to socioclinical parameters.

Among 78 E. coli strains, the highest resistance to beta-lactams was observed with Ampicillin (65\%), Ticarcillin (61\%), Amoxicillin-clavulanic acid (45\%), Cefalotin (41\%) and Cefotaxime (33\%) while the lowest frequency of resistance was found with Imipenem (2\%), Ertapenem (2\%) and Cefepime (7\%) (Table 3). The majority of E. coli strains (55\%) was MDR. The MDR phenotype Ampicillin/Nalidixic acid/Trimethoprim-

Sulfamethoxazole was the most prevalent $(70 \%)$ in E. coli strains. Resistance to Ampicillin ( $p<0.001)$, Ticarcillin ( $p$ $<0.001)$, Amoxicillin-clavulanic acid ( $\mathrm{p}<0.001)$, Cefalotin $(\mathrm{p}<0.001)$, Cefoxitin $(\mathrm{p}=0.025)$, Cefotaxime $(\mathrm{p}<0.001)$, Ceftazidime ( $\mathrm{p}<0.001)$, Nalidixic Acid $(\mathrm{p}<0.001)$, Ciprofloxacin $(\mathrm{p}=0.002)$ and Ofloxacin $(\mathrm{p}<0.001)$ were more common in MDR-E. coli compared to non-MDR -E. coli-isolates (Table 3). Antibiotics multidrugresistance has been observed more frequently in women compared to men $(\mathrm{p}<0.0001)$.

Of $45 \mathrm{~K}$. pneumoniae strains tested, the highest rates of antibiotics resistance were observed with Cefalotin (58\%), Cefotaxime (56\%), Amoxicillin-clavulanic acid (46\%) and Ceftazidime (47\%) whereas the lowest frequency of resistance was obtained with Cefepime (4\%), Imipenem (4\%) and Ertapenem (4\%) (Table 3). K. pneumoniae strains were $57 \%$ MDR, predominantly isolated from patients $\leq$ 5 years $(\mathrm{p}=0.002)$. The MDR phenotype Amoxicillin- clavulanic acid/Cefotaxime/Trimethoprim-

Sulfamethoxazole was most common $(52 \%)$ in $K$. pneumoniae strains. Resistance to Amoxicillinclavulanic acid, Cefalotin, Cefoxitin, Cefotaxime, Ceftazidime, nalidixic acid and Ofloxacin was significantly more frequently observed in MDR-K. pneumoniae compared to non-MDR-K. pneumoniae isolates (Table 3).

We also compared the resistance of E. coli and $K$. pneumoniae strains to antibiotics. $K$. pneumoniae strains of were more resistant to cefotaxime compared to those of E. coli $(56 \%$ vs $33 \%$; p $=0.024)$ (Table 3$)$. Regarding quinolones, E. coli strains were more resistant to nalidixic acid $(51 \%$ vs $22 \% ; \mathrm{p}=0.002)$ and to Ciprofloxacin ( $34 \%$ vs $13 \%, \mathrm{p}=0.01)$ compared to K. pneumoniae strains while resistance to Ofloxacin was similar between the two types of bacteria (39\% vs $28 \%$; $\mathrm{p}=0.226)$ (Table 3).

For aminoglycosides, the resistance of strains of $E$. coli and $K$. pneumoniae was evaluated with antibiotics such as Gentamicin (25\% vs $28 \%$ ), Tobramycin ( $28 \%$ vs $24 \%$ ) and Amikacin ( $7 \%$ vs $4 \%$ ). It was similar for the three antibiotics between E. coli and $K$. pneumoniae (Table 3). Resistance of $K$. pneumoniae to Cefotaxime ( $80 \%$ vs $43 \% ; \mathrm{p}=0.044)$ and Trimethoprim-Sulfamethoxazole $(73 \%$ vs $53 \%$; p <0.0001) was significantly higher in men compared to women. Among MDR isolates, we 


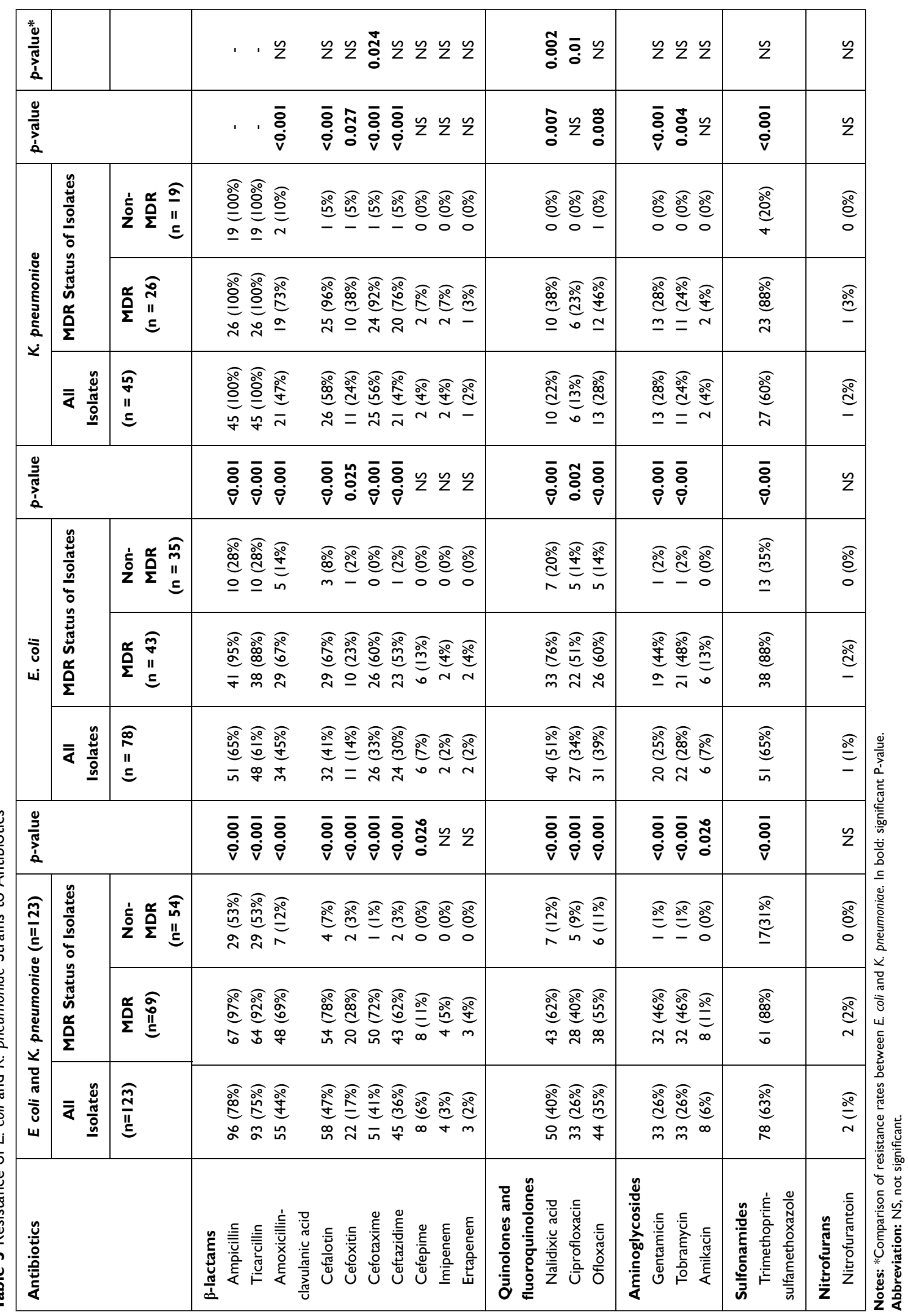


identified one strain of $E$. coli and $K$. pneumoniae resistant to $14 / 18(77 \%)$ and $13 / 18(72 \%)$ of antibiotics tested.

\section{Discussion}

The overreaching goal of this study was to describe the epidemiology of E. coli and K. pneumoniae uropathogenic strains isolated in Franceville in South-eastern Gabon and to determine their resistance profiles to common antibiotics.

The epidemiological profile of uropathogenic bacteria varies from one region to another. ${ }^{15}$ As a result, the knowledge of the local epidemiology, as well as its evolution is crucial in the selection of an effective first-line antibiotic therapy adapted to each region. ${ }^{15}$ Of the 1086 patients' CBEUs, the prevalence of urinary tract infections was $29.2 \%$. This prevalence is lower than $59.8 \%$ reported in a previous study in Cameroon. ${ }^{16}$ E. coli and $K$. pneumoniae represented $44.9 \%$ of the germs involved in the etiology of urinary tract infections with $28.7 \%$ and $16.2 \%$ respectively. Such prevalence is similar to $24.5 \%$ for E. coli and $18.4 \%$ for K. pneumoniae reported in an earlier study in Nigeria. ${ }^{17}$ However, the prevalence of E. coli found in UTIs is significantly lower than those between $60 \%$ and $90 \%$ reported in $\mathrm{Chad}^{18}$ Madagascar; ${ }^{19}$ Rwanda $^{20}$ and Morocco. ${ }^{21}$ We found that urinary tract infections due to E. coli mainly affected women, which is in agreement with similar studies carried out in Cameroon ${ }^{22}$ and Nigeria. ${ }^{23}$ This could be explained on the one hand by the proximity of the urethral, anal and vaginal orifices in women and on the other hand by poor hygiene practices as well as pregnancies responsible for a biased immune response favorable to microbial agents development in pregnant women. ${ }^{22,24}$ We also observed that the urinary tract infection with $K$. pneumoniae was more frequent among young patients $(\leq 5$ years $)$ and the older patients ( $\geq 50$ years). Our results are in agreement with those reported in a previous study. ${ }^{22}$ These two groups of patients are at higher risk. ${ }^{22}$ Indeed, in the elderly, the risk of urinary tract infection increases due to the decline of the immune system efficiency and decreased functional autonomy. ${ }^{8}$ In children aged $\leq 5$ years, UTI incidence is about $5 \%$ in girls and $20 \%$ in uncircumcised boys. For febrile infants in the first two months of life and during the first 6 months, the risk of developing an UTI is 10 to 12 times higher in uncircumcised boys. ${ }^{25}$ This susceptibility of developing UTIs could be attributed to a less robust immune system. ${ }^{25}$
E. coli and K. pneumoniae isolated strains have shown strong resistance to several antibiotics. The resistance of E. coli to Ampicillin and Ticarcillin was $65 \%$ and $61 \%$, respectively. Similar resistance rates have been reported on an outpatient basis in West Africa, ${ }^{26}$ Madagascar, ${ }^{19}$ the Central African Republic ${ }^{27}$ and Chad. ${ }^{18}$ These high resistance rates could explain why aminopenicillins and carboxypenicillins are no longer recommended for the probabilistic treatment of UTIs. ${ }^{28}$

The resistance rates of E. coli and K. pneumoniae to amoxicillin-clavulanic acid were $45 \%$ and $47 \%$, respectively. These prevalence are higher than those ranging between 25 and 35\% reported in France. ${ }^{8}$ However, this resistance rate is similar to that of $50 \%$ reported in Rwanda in patients of community origin. ${ }^{20}$ The resistance of these two bacteria to amoxicillin-clavulanic acid reported in this study is much lower than that observed in Senegal, $60.17 \%$ for E. coli and $73.18 \%$ for K. pneumoniae, respectively. ${ }^{29}$

K. pneumoniae strains have shown a higher resistance rate of $76.09 \%$ to amoxicillin-clavulanic acid in Pakistan. ${ }^{30}$ These high rates of antibiotic resistance could be explained by the broad probabilistic prescription of these antibiotics, particularly in outpatient medicine in the absence of CBEUs results. ${ }^{22}$

The resistance rate of E. coli to 3rd generation cephalosporins was $33 \%$ and $30 \%$ for cefotaxime and ceftazidime, respectively. These resistance rates were higher than those ranging from 0 to $5 \%$ observed in the Central African Republic, ${ }^{27}$ Sudan, ${ }^{31}$ and Madagascar. ${ }^{19}$ The resistance of $E$. coli to ceftazidime was similar to that of $29.1 \%$ obtained in Rwanda. ${ }^{20}$ On the other hand, the resistance of the strains of $K$. pneumoniae to 3rd generation cephalosporins was $56 \%$ for Cefotaxime and $47 \%$ for Ceftazidime. These resistance rates are in line with those reported by studies in Pakistan and Senegal, which were respectively $54.35 \%$ for 3 rd generation cephalosporins ${ }^{30}$ and $57.85 \%$ for Cefotaxime. ${ }^{29}$ A very high $84 \%$ resistance rate of K. pneumoniae to Ceftazidime has been reported in India. $^{32}$

This E. coli strains resistant to third-generation cephalosporins $(\mathrm{C} 3 \mathrm{G})$ could be explained by their acquisition of a plasmid-extended-spectrum beta-lactamase (ESBL). ${ }^{8,24}$ Previous studies carried out in Gabon reported high prevalence of bacterial strains producing ESBLs. ${ }^{33,34}$ In addition, the Global Antimicrobial Resistance Surveillance Report found that five out of six (5/6) and six out of six regions (6/6) reported $E$. coli and $K$. pneumoniae 
resistance $>50 \%$ to $\mathrm{C} 3 \mathrm{Gs}$, respectively. ${ }^{35}$ These findings were in agreement with the results of this study.

Carbapenems (Imipenem and Ertapenem) had good efficacy on E. coli and K. pneumoniae strains with resistance rates of $2 \%$ and $4 \%$, which corroborated the results obtained by Leopold et al. ${ }^{36}$

Quinolones retained acceptable activity against K. pneumoniae strains with resistance rates of $13 \%$ to $28 \%$. However, this resistance was higher in strains of E. coli ranging from $34 \%$ to $51 \%$. An earlier study conducted in sub-Saharan Africa reported E. coli strain resistance to quinolones ranging between 0 and $98 \%{ }^{36}$ The first-line use of fluoroquinolones as a probabilistic treatment against these bacteria could explain the emergence of their resistance to quinolones. ${ }^{37}$ Aminoglycoside activity was conserved across all E. coli and K. pneumoniae strains with resistance rates ranging between $4 \%$ and $28 \%$. Amikacin has been the most active antibiotic among the aminoglycosides. Resistance to aminoglycosides observed in this study was similar to that of $16.7 \%$ and $21.8 \%$ reported in $\operatorname{Iran}^{38}$ and between $8 \%$ and $14 \%$ observed in Morocco. ${ }^{21}$ The apparently preserved efficacy of aminoglycosides could be explained by their frequent parenteral administration, limiting use. In contrast, the resistance of E. coli and K. pneumoniae to Cotrimoxazole were $65 \%$ and $60 \%$, respectively. The resistance rates to Cotrimoxazole of $80 \%$ in the Central African Republic; $69.5 \%$ in Madagascar and $55 \%$ in Morocco have been reported in previous studies. ${ }^{19,21,27}$ This high resistance of E. coli and K. pneumoniae to Cotrimoxazole could explain its exclusion in the probabilistic treatment of uncomplicated urinary tract infections. Nitrofurantoin appeared to be the most active antibiotic against E. coli and $K$. pneumoniae uropathogenic strains.

We found that $57 \%$ of E. coli and K. pneumoniae isolated were MDR. The presence of these MDR strains suggests that inappropriate use of antibiotics without medical prescription is taking place. This is mainly due to the lack of clinical microbiology laboratory, ${ }^{39,40}$ which tends to promote self-medication, increasing the risk of selection of resistant bacteria leading to the emergence of multidrug resistant bacteria. ${ }^{41,42}$

\section{Conclusion}

This study showed a high prevalence of urinary tract infections with great involvement of $E$. coli and K. pneumoniae strains. These bacteria have shown high levels of resistance to beta-lactams, quinolones and cotrimoxazole, while Nitrofurantoin, Amikacin, Imipenem and Ertapenem remain the most active antibiotics against $E$. coli and $K$. pneumoniae uropathogenic strains. The levels of bacterial resistance observed in this study requires the use of antibiotics adapted to the local epidemiology and the promotion of the antimicrobial resistance surveillance by the health authorities.

\section{Abbreviations}

$\mathrm{CBEU}$, Cytobacteriological examination of urine; CFU, Colony forming unit; CLED, Cystine-Lactose-ElectrolytesDeficient; $\mathrm{C} 3 \mathrm{G}$, third generation cephalosporins; EMB, Eosine Methylene Blue; ESBL, Extended-spectrum-betalactamase; EUCAST, European Committee on Antimicrobial Susceptibility Testing; GNB, Gram negative bacilli; McC, Mac Conkey; MDR, Multidrug resistance; MH, Mueller-Hinton; UTI, Urinary tract infection.

\section{Data Sharing Statement}

Data supporting the conclusions of this study will be made available on request to the corresponding author.

\section{Acknowledgments}

The authors thank all the staff of the Medical Research Unit. We also thank the study participants for their kind participation.

\section{Author Contributions}

All authors made a significant contribution to the work reported, whether that is in the conception, study design, execution, acquisition of data, analysis and interpretation, or in drafting, revising or critically reviewing the article; gave final approval of the version to be published; have agreed on the journal to which the article has been submitted; and agree to be accountable for all aspects of the work.

\section{Funding}

There is no funding to report.

\section{Disclosure}

The authors declare that they have no conflicts of interest for this work.

\section{References}

1. Gonzalez CM, Schaeffer AJ. Treatment of urinary tract infection: what's old, what's new, and what works. World J Urol. 1999;17 (6):372-382. doi:10.1007/s003450050163 
2. Gajdacs M, Batori Z, Abrok M, Lazar A, Burian K. Characterization of resistance in gram-negative urinary isolates using existing and novel indicators of clinical relevance: a 10 -year data analysis. Life 2020;10(2):16. doi:10.3390/life10020016

3. WHO. Système mondial de surveillance de la résistance aux antimicrobiens: Manual de mise en oeuvre initiale. Zurich: World Health Organization; 2016.

4. Linhares I, Raposo T, Rodrigues A, Almeida A. Frequency and antimicrobial resistance patterns of bacteria implicated in community urinary tract infections: a ten-year surveillance study (2000-2009). BMC Infect Dis. 2013;13:19. doi:10.1186/1471-2334-13-19

5. Gajdacs M, Burian K, Terhes G. Resistance levels and epidemiology of non-fermenting gram-negative bacteria in urinary tract infections of inpatients and outpatients (RENFUTI): a 10-year epidemiological snapshot. Antibiotics. 2019;8(3)

6. Gajdacs M, Doczi I, Abrok M, Lazar A, Burian K. Epidemiology of candiduria and Candida urinary tract infections in inpatients and outpatients: results from a 10-year retrospective survey. Cent Eur J Urol. 2019;72(2):209-214. doi:10.5173/ceju.2019.1909

7. Sire JM, Nabeth P, Perrier-Gros-Claude JD, et al. Antimicrobial resistance in outpatient Escherichia coli urinary isolates in Dakar, Senegal. $J$ Infect Dev Ctries. 2007;1(3):263-268. doi:10.3855/jidc.362

8. SPILF. Diagnostic et antibiothérapie des infections urinaires bactériennes communautaires de l'adulte. Paris: SPILF; 2015:1-43.

9. Gajdacs M, Albericio F. Antibiotic resistance: from the bench to patients. Antibiotics. 2019;8(3):129. doi:10.3390/antibiotics8030129

10. De Francesco MA, Ravizzola G, Peroni L, Negrini R, Manca N. Urinary tract infections in Brescia, Italy: etiology of uropathogens and antimicrobial resistance of common uropathogens. Med Sci Monit. 2007;13(6):BR136-44.

11. Neto JAD, Martins ACP, Silva LDMD. Community acquired urinary tract infection: etiology and bacterial susceptibility. Acta Cir Bras. 2003;18(suppl 5):33-36. doi:10.1590/S0102-86502003001200012

12. Hay AD, Birnie K, Busby J, Delaney B, Downing H, Dudley J. The diagnosis of urinary tract infection in young children (DUTY): a diagnostic prospective observational study to derive and validate a clinical algorithm for the diagnosis of urinary tract infection in children presenting to primary care with an acute illness. Health Technol Assess (Rockv). 2016;20(51):1-294. doi:10.3310/hta20510

13. SFM/EUCAST. Comité de l'Antibiogramme de la Sociéte Française de Microbiologie: recommandations. Paris; 2018. Available from: https://www.sfm-microbiologie.org/wp-content/uploads/2018/12/ CASFMV2 SEPTEMBRE2018.pdf. Accessed February 9, 2021.

14. Magiorakos AP, Srinivasan A, Carey RB, et al. Multidrug-resistant, extensively drug-resistant and pandrug-resistant bacteria: an international expert proposal for interim standard definitions for acquired resistance. Clin Microbiol Infect. 2012;18(3):268-281. doi:10.1111/ j.1469-0691.2011.03570.x

15. El Bouamri MC, Arsalane L, Kamouni Y, et al. Current antibiotic resistance profile of uropathogenic Escherichia coli strains and therapeutic consequences. Prog Urol. 2014;24(16):1058-1062.

16. Nzalie RN, Gonsu HK, Koulla-Shiro S. Bacterial etiology and antibiotic resistance profile of community-acquired urinary tract infections in a cameroonian city. Int J Microbiol. 2016;2016:3240268. doi:10.1155/2016/3240268

17. El-Mahmood MA. Antimicrobial susceptibility pattern of pathogenic bacteria causing urinary tract infections at the Specialist Hospital, Yola, Adamawa state, Nigeria. J Clin Med Res. 2009;1(1):1-8.

18. Yandai FH, Ndoutamia G, Nadlaou B, Barro N. Prevalence and resistance profile of Escherichia coli and Klebsiella pneumoniae isolated from urinary tract infections in N'Djamena, Tchad. Int J Biol Chem Sci. 2019;13(4):2065-2073. doi:10.4314/ijbcs.v13i4.13

19. Randrianirina F, Soares JL, Carod JF, et al. Antimicrobial resistance among uropathogens that cause community-acquired urinary tract infections in Antananarivo, Madagascar. J Antimicrob Chemother. 2007;59(2):309-312. doi:10.1093/jac/dk1466
20. Muvunyi CM, Masaisa F, Bayingana C, et al. Decreased susceptibility to commonly used antimicrobial agents in bacterial pathogens isolated from urinary tract infections in Rwanda: need for new antimicrobial guidelines. Am J Trop Med Hyg. 2011;84(6):923-928. doi:10.4269/ajtmh.2011.11-0057

21. Arsalane L, Kamouni Y, Yahyaoui H, Bennouar N, Berraha M, Zouhair S. Profil actuel de résistance aux antibiotiques des souches d'Escherichia coli uropathogènes et conséquences thérapeutiques. Prog Urol. 2014;24(16):1058-1062. doi:10.1016/j.purol.2014.09.035

22. Gonsu Kamga H, Nzengang R, Toukam M, Sando Z, Koulla Shiro S. Phénotypes de résistance des souches d'Escherichia coli responsables des infections urinaires communautaires dans la ville de Yaoundé (Cameroun). Afr J Pathol Microbiol. 2014;3:1-4. doi:10.4303/ajpm/ 235891

23. Kolawole AS, Kolawole OM, Kandaki-Olukemi YT, Babatunde SK, Durowade KA, Kolawole CF. Prevalence of urinary tract infections (UTI) among patients attending Dalhatu Araf Specialist Hospital, Lafia, Nasarawa state, Nigeria. Int J Med Sci. 2010;1(5):163-167.

24. Behzadi P, Urban E, Matuz M, Benko R, Gajdacs M. The role of gram-negative bacteria in urinary tract infections: current concepts and therapeutic options. Adv Exp Med Biol. 2020.

25. Chang SL, Shortliffe LD. Pediatric urinary tract infections. Pediatr Clin North Am. 2006;53(3):379-400. doi:10.1016/j.pcl.2006.02.011

26. Bernabe KJ, Langendorf C, Ford N, Ronat J-B, Murphy RA. Antimicrobial resistance in West Africa: a systematic review and meta-analysis. Int $J$ Antimicrob Agents. 2017;50(5):629-639. doi:10.1016/j.ijantimicag.2017.07.002

27. Hima-Lerible H, Menard D, Talarmin A. Antimicrobial resistance among uropathogens that cause community-acquired urinary tract infections in Bangui, Central African Republic. J Antimicrob Chemother. 2003;51(1):192-194. doi:10.1093/jac/dkg053

28. Benhiba I, Bouzekraoui T, Zahidi J. Epidémiologie et antibiorésistance des infections urinaires à entérobactéries chez l'adulte dans le CHU de Marrakech et implication thérapeutique. Revue Africaine. 2015;1(4).

29. Dia ML, Chabouny H, Diagne R. Profil antibiotypique des bactéries uropathogènes isolées au CHU de Dakar. Revue Africaine. 2015;1(4).

30. Ullah F, Malik SA, Ahmed J. Antimicrobial susceptibility pattern and ESBL prevalence in Klebsiella pneumoniae from urinary tract infections in the North-West of Pakistan. Afr J Microbiol Res. 2009;3 (11):676-680.

31. Ahmed AA, Osman H, Mansour AM, et al. Antimicrobial agent resistance in bacterial isolates from patients with diarrhea and urinary tract infection in the Sudan. Am J Trop Med Hyg. 2000;63(5-6):259-263. doi:10.4269/ajtmh.2000.63.259

32. Singh NP, Goyal R, Manchanda V, Das S, Kaur I, Talwar V. Changing trends in bacteriology of burns in the burns unit, Delhi, India. Burns. 2003;29(2):129-132. doi:10.1016/S0305-4179(02)00249-8

33. Schaumburg F, Alabi A, Kokou C, et al. High burden of extended-spectrum beta-lactamase-producing Enterobacteriaceae in Gabon. J Antimicrob Chemother. 2013;68(9):2140-2143. doi:10.1093/jac/dkt164

34. Yala J-F, Mabika Mabika R, Bisseye C, et al. Phenotypic and genotypic characterization of extended-spectrum-beta-lactamases producing-enterobacteriaceae (ESBLE) in patients attending Omar Bongo Ondimba military hospital at Libreville (Gabon). $J \mathrm{Mol}$ Microbiol Biotechnol. 2016;4(6):944-949.

35. WHO. Antimicrobial Resistance: Global Report on Surveillance: World Health Organization. 2014.

36. Leopold SJ, van Leth F, Tarekegn H, Schultsz C. Antimicrobial drug resistance among clinically relevant bacterial isolates in sub-Saharan Africa: a systematic review. J Antimicrob Chemother. 2014;69 (9):2337-2353. doi:10.1093/jac/dku176

37. Dromigny JA, Nabeth P. Distribution and susceptibility of bacterial urinary tract infections in Dakar, Senegal. Int J Antimicrob Agents. 2002;20(5):339-347. doi:10.1016/S0924-8579(02)00196-6 
38. Naziri Z, Derakhshandeh A, Soltani Borchaloee A, Poormaleknia M, Azimzadeh N. Treatment failure in urinary tract infections: a warning witness for virulent multi-drug resistant ESBL- producing escherichia coli. Infect Drug Resist. 2020;13:1839-1850. doi:10.2147/IDR. S256131

39. Radyowijati A, Haak H. Improving antibiotic use in low-income countries: an overview of evidence on determinants. Soc Sci Med. 2003;57(4):733-744. doi:10.1016/S0277-9536(02)00422-7

40. Tadesse BT, Ashley EA, Ongarello S, et al. Antimicrobial resistance in Africa: a systematic review. BMC Infect Dis. 2017;17(1):616. doi:10.1186/s12879-017-2713-1
41. Grigoryan L, Burgerhof JG, Haaijer-Ruskamp FM, et al. Is self-medication with antibiotics in Europe driven by prescribed use? $J$ Antimicrob Chemother. 2007;59(1):152-156. doi:10.1093/jac/ dk1457

42. Planta MB. The role of poverty in antimicrobial resistance. $J A m$ Board Fam Med. 2007;20(6):533-539. doi:10.3122/jabfm.2007 j.06.070019

\section{Publish your work in this journal}

Infection and Drug Resistance is an international, peer-reviewed openaccess journal that focuses on the optimal treatment of infection (bacterial, fungal and viral) and the development and institution of preventive strategies to minimize the development and spread of resistance. The journal is specifically concerned with the epidemiology of antibiotic resistance and the mechanisms of resistance development and diffusion in both hospitals and the community. The manuscript management system is completely online and includes a very quick and fair peerreview system, which is all easy to use. Visit http://www.dovepress.com/ testimonials.php to read real quotes from published authors. 